\title{
Pre-Analysis Plan \\ Understanding the resource curse: \\ A survey experiment in Tanzania
}

\author{
Alexander Cappelen Odd-Helge Fjeldstad Donald Mmari \\ Ingrid Hoem Sjursen Bertil Tungodden
}

July 10th 2015

\section{Contents}

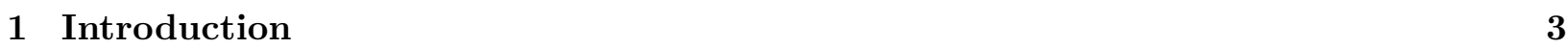

\begin{tabular}{|ll|l}
2 & Research strategy & 5
\end{tabular}

2.1 Recruitment, location and sample . . . . . . . . . . . . . . . . . . . 5

\begin{tabular}{ll|l}
\hline & Design & 5
\end{tabular}

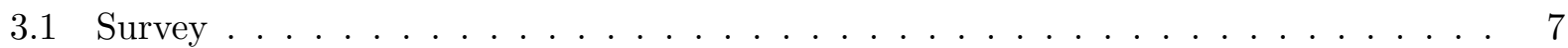

3.1 .1 Background variables $\ldots \ldots \ldots \ldots \ldots \ldots$

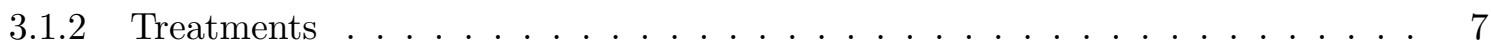

3.1 .3 Outcome variables . . . . . . . . . . . . . . . . . . . . . . 8

3.1 .4 Behavioural measures . . . . . . . . . . . . . . . . . . . . . . 8

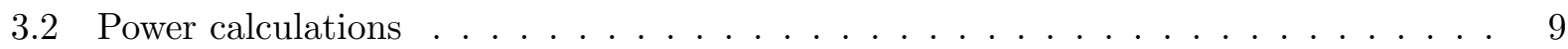

$3.2 .1 \quad$ Calculations for Tanzania $\ldots \ldots \ldots \ldots \ldots$. . . . . . . . . . . . . 9

\begin{tabular}{|lll}
\hline 4 & Empirical strategy & 9
\end{tabular}

4.1 Main analysis . . . . . . . . . . . . . . . . . . . . . . . . . . 9 9

4.1 .1 Heterogeneity . . . . . . . . . . . . . . . . . . . . 10

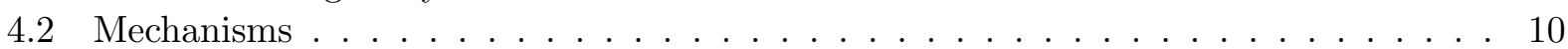

4.3 Behaviour . . . . . . . . . . . . . . . . . . . . . . . . . . . . . 12

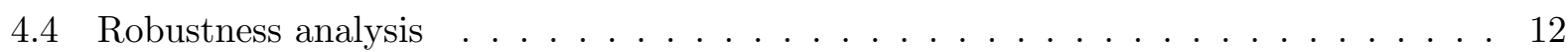

4.5 Specification and analysis $\ldots \ldots \ldots \ldots \ldots \ldots \ldots \ldots \ldots \ldots$

4.5 .1 Main hypothesis . . . . . . . . . . . . . . . . . . . . . . 13

4.5 .2 Heterogeneity analysis $\ldots \ldots \ldots \ldots \ldots \ldots \ldots$

4.5 .3 Mechanisms . . . . . . . . . . . . . . . . . . . . . . . . . . 13

4.5 .4 Behaviour . . . . . . . . . . . . . . . . . . . . . . . . 13

4.5 .5 Robustness analysis $\ldots \ldots \ldots \ldots \ldots \ldots \ldots$

\begin{tabular}{|ll|r}
\hline 5 & References & 14
\end{tabular}

\begin{tabular}{|l|l}
\hline A Hypothesis testing & $\mathbf{1 5}$
\end{tabular}

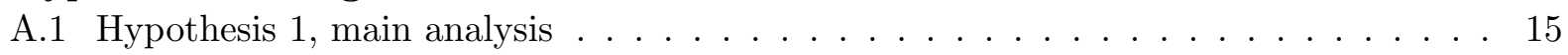

A.2 Hypothesis 8 , robustness analysis $\ldots \ldots \ldots \ldots \ldots \ldots \ldots$ 
\begin{tabular}{lll}
\hline B Survey & 15
\end{tabular}

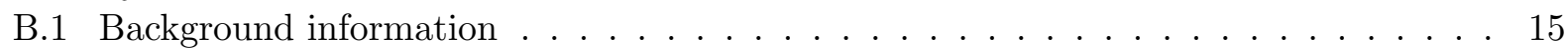

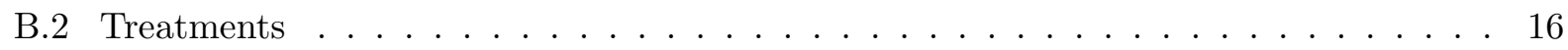

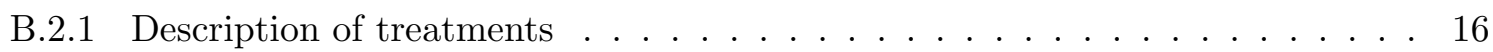

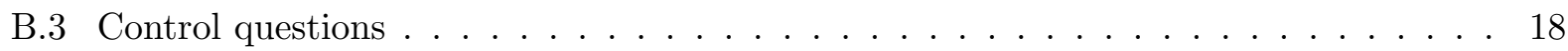

B.4 Attitudes and beliefs $\ldots \ldots \ldots \ldots \ldots \ldots \ldots \ldots \ldots$

B.5 Behavioural measures . . . . . . . . . . . . . . . . . . . . . . . . 19

B.5.1 Trust game . . . . . . . . . . . . . . . . . . . . . . . . . . 19

B.5.2 Cheating game . . . . . . . . . . . . . . . . . . 22

B.6 Interview and interviewer details $\ldots \ldots \ldots \ldots \ldots \ldots \ldots \ldots$ 


\section{Introduction}

Tanzania has discovered large reservoirs of off shore natural gas, and might become a large exporter of liquefied natural gas (LNG) during the next decades. With this comes the promise of significant petro-revenues to the Tanzanian government, and prospects of improved economic and social conditions for the country's population. However, the empirical literature suggests that natural resource wealth constitutes a considerable challenge. Natural resource wealth is associated with lower economic growth (Sachs and Warner 1995, Sachs and Warner 1999, Mehlum et al. 2006); prolonged authoritarian regimes (Aslaksen 2010, Ross 2001, 2009, Tsui 2011, Andersen and Aslaksen 2013); corruption (Vicente 2010, Leite and Weidmann 2002, Treismann 2007, Busse and Gröning 2013); and violent conflict (Collier and Hoeffler 2004).

While there seems to be a consensus that such a thing as a "resource curse" exists, there is large heterogeneity in the economic, social and political outcomes of natural resource wealth. Researchers have proposed different channels that can explain these diverging experiences. The present study will draw on the political economy literature that focuses on the quality of institutions, governance and democracy (Ross 2015, Busse and Gröning 2013).

A central theme in this literature is that natural resource wealth creates so-called rentier effects; current and future resource rents increase the value of staying in power and enable the political leadership to increase the likelihood of being re-elected by reducing non-resource tax rates or increase patronage (Robinson et al. 2006). Rents from natural resources might also induce individuals to shift from productive activities to rent seeking, i.e. non-productive activities with the aim of capturing some of the resource wealth, such as political lobbying and corruption (Mehlum et al. 2006, Busse and Gröning 2013).

Studies of cross-national data have shown negative correlations between natural resource wealth and taxation and lend some support to the hypotheses that resource wealth decreases non-resource tax revenue (Ross, 2012) and increases corruption. However, very few studies have explored the underlying mechanisms of these effects, and even fewer have investigated how resource rents affect citizens political and economic behaviour. A few exceptions exists: McGuirk (2013) finds statistically significant within-country correlations between natural resource rents and i) reduced perceived taxation and ii) reduced demand for democratic governance. Paler (2013) finds that i) taxes motivate citizens more than windfalls to hold politicians accountable; and ii) citizens care more about wasted revenue when they pay taxes in a field experiment in Indonesia. Finally, in a natural experiment in Sao Tome \& Principe, Vicente (2010) finds an increase in perceived corruption in public services after the announcement of oil discoveries.

This research project aims to contribute to the scarce body of micro-level empirical investigations of the resource curse by investigating the effect of natural resource rents on citizens political attitudes and behaviour. In addition to look at citizens willingness to pay tax and engage in corrupt activities, we will also examine people's trust in the government. While trust has been shown to be an important determinant of economic growth, we have not found any studies investigating the effect of natural resource rents on the level of trust in a society.

The research questions we seek to answer are the following:

How do expectations about resource revenues in a country affect

- people's willingness to pay taxes?

- people's willingness to engage in corrupt/rent-seeking activities?

- people's trust in the government?

To answer these questions, we will conduct a survey experiment that will also include incentivised games. In the experiment, respondents will first answer some key background questions. 
They are then randomly assigned to a control or one of four treatment groups. In all treatments, we will provide information about the estimated total value of the gas revenues, but how the totals are illustrated will be varied. We use a $2 \times 2$ design to study if the results are sensitive to whether the revenues are illustrated (a) in per capita or population terms and (b) in totals or in terms of the interest that can be generated in infinity if the money is saved.

- Treatment 1: Annual real return if gas revenues are saved, per capita

- Treatment 2: Annual real return if gas revenues are saved, for all Tanzanians

- Treatment 3: Total value, per capita

- Treatment 4: Total value, for all Tanzanians

We believe that this design captures two distributional concerns that are implicit in the resource revenue debate, namely

1. The extent to which the resource revenues are considered to belong to the individuals or to society

2. The extent to which future generations are considered to be entitled to the resource revenues

The information manipulation may be important both from a policy perspective, since it may inform policy-makers about the impact of how different informational responses may affect the public, but also because it may shed light on how the different informational approaches affect the mindset of people. In particular, we will investigate whether the per capita approach makes people adopt a more individualistic perspective and the possibility to save the resource revenues makes people more concerned about future generations.

The respondents in the control group will not receive any information about gas revenues, only some general information about the population, number of regions, and the gross national income of Tanzania. The general information will be provided to all groups.

- Control: General information about Tanzania

The purpose of the treatments is to generate exogenous variation in expectations about gas revenues, by increasing the salience of existing expectations among those who already know about them, and by creating expectations among those who do not know about gas revenues.

After receiving the treatment or control group information, respondents answer a series of questions intended to capture willingness to pay taxes, willingness to engage in corruption and trust in the government. The treatment manipulations allow us to study the causal effect of increased expectations about gas revenues on willingness to pay tax and to engage in corrupt activities, as well as trust in the government by simply reminding the participants in the treatment conditions about the fact that Tanzania has discovered large reservoirs of natural gas.

In the last part of the experiment, respondents play an incentivised game. We have developed two games.

- Game 1 intends to measure trust in other citizens in economic decisions

- Game 2 intends to measure cheating behaviour (proxy for willingness to engage in corrupt activities)

The incentivised games provide us with behavioural measures of how information about gas revenues, and the way in which it is presented, affects trust and cheating behaviour in society. Respondents will be randomly assigned to one of the two games.

This pre-analysis plan presents the data sources and the design of the experiment. It also describes empirical strategies and the hypotheses to be tested. 
The plan was registered AEA RCT registry July 10th 2015. A pilot of the survey was carried out in the field July 8th - 10th, but we did not have access to the data before completing this pre-analysis plan.

\section{Research strategy}

To inform the research design we conducted focus groups and a small pilot in Dar es Salaam in December 2014, a web-based pilot in Norway in May 2015, and focus groups in Dar es Salaam in May and June 2015.

\subsection{Recruitment, location and sample}

The respondents will be recruited through household interviews where households are randomly selected.

The study will be conducted in Tanzania. Three regions in Tanzania are of particular interest for the study: Dar es Salaam, Mtwara and Lindi. Mtwara and Lindi were chosen because these are the regions closest to the off-shore gas reservoirs. The planned LNG-plant will be located in this area. Onhore gas is already being extracted here and a pipeline for transporting the onshore-gas to Dar es salaam has been constructed.

In Dar es Salaam we will include all three municipalities: Ilala, Kinondoni and Temeke. In Lindi, Lindi Municipal is the only urban district and it was therefore selected without randomization. In addition, the two rural districts Lindi (rural) and Nachingwea were randomly selected. In Mtwara, Mtwara Municipal was intentionally selected from the two urban districts to ensure that we include a costal district. Masasi and Newala were randomly selected among the rural districts. Within each of the 9 districts, 3 wards have been randomly selected using data from the 2012 household census. Within each of the 27 wards, three villages/streets will be randomly selected in the field. Within each of these 81 villages/streets, between 35 and 40 households will be randomly selected in the field.

\section{Design}

This section describes the design of the survey and informational treatments. The sequence of the different parts is as follows

1. Background questions

2. Control or one of four treatment information videos

3. Attitudes and beliefs

4. One of two incentivised games

5. Interview and interviewer details

A schematic representation of the research design is provided in Figure 1 below.

The survey will be conducted using tablets and Qualtrics Offline Surveys Application (http://www.qualtrics.com). The application allows us to use the Qualtrics software without wi-fi, and also enables integration of the survey with the treatment and control videos. It also computerizes the randomization of videos and the experimental game. The detailed survey can be found in the Appendix B. 
Figure 1: Research design

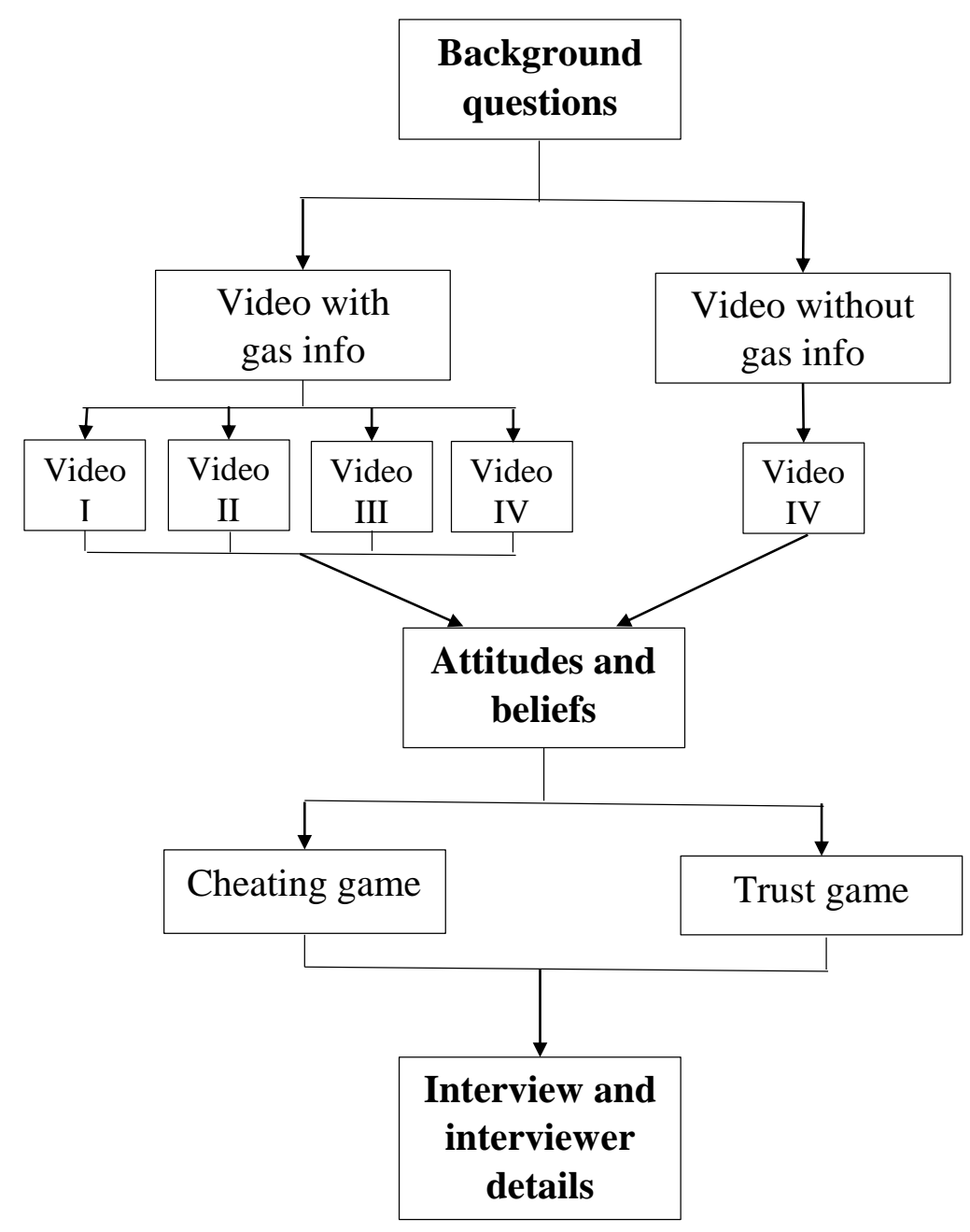




\subsection{Survey}

\subsubsection{Background variables}

In this part of the survey, we collect background information. In the main analysis, we will control for the following pre-specified variables:

- Gender: Dummy variable $(1=$ Male, $0=$ Female $)$

- Age: Count variable

- Marital status: Dummies for married, unmarried, divorced, widow(er)

- Education: No formal education, completed primary school, completed secondary school, higher education

- Occupation: Unemployed, self-employed, public sector and private sector

- Region: Dummy variable $(1=$ Dar es Salaam, $0=$ all other regions $)$

- Home region: Dummy variable $(1=$ Dar es Salaam, $0=$ all other regions $)$

This information will also be used to check the balance across groups, and some of it (specified below) will be used to investigate heterogeneity in treatment effects.

\subsubsection{Treatments}

In this part of the survey, the respondents are randomly assigned to one of four treatments or a control group. All groups will be presented with an information video with illustrations, soundtrack and text in Kiswahili. It will be displayed on the enumerator's tablet and the respondent will be provided with a headset to hear the sound. The major difference between the control and treatment group videos is that the control condition does not provide any information about gas or gas revenues. In all treatments, we will report the estimated total value of the gas revenues, but the treatments will vary with respect to how the totals are illustrated. The purpose of the treatment is to generate exogenous variation in the mindset of respondents when thinking about gas revenues. The idea is that providing information about gas to the respondents increases the salience of their expectations / cause them to form new expectations. We want to test whether the expectations causally affect attitudes towards tax and corruption, and trust in the government. As a robustness check we also want to investigate whether the different informational approaches have psychological effects on attitudes, beliefs and behaviour of people. The content of the videos is explained in detail in the Appendix B.2.1.

After watching the control or one of the four treatment videos, the respondents will be asked one (if in the control group) or two (if in one of the treatment groups) control questions. These are formulated to test whether the treatments made the expectations about gas revenues more salient and whether the way the information was illustrated affected interpretation of the size of the gas revenues (treatment groups), as well as whether the information provided was new to the respondents (all groups). The formulation of the questions is provided in the mechanism section below.

Because we mention money (in large amounts) in all four treatments, as well as in the control, any treatment effects we might find will not be driven by the fact that we have mentioned money. 


\subsubsection{Outcome variables}

In this part of the survey, the main outcome questions, as well as questions that will aid our understanding of mechanisms that work to influence these, are posed.

We define the following questions as main outcome questions:

1. In order for Tanzania to achieve a desired social and economic development in the years to come, the taxes paid by ordinary Tanzanians, like the VAT, should

- Decrease a lot (1), decrease (2), stay the same (3), increase (4), increase a lot (5)

2. In the years to come, I expect the extent of corrupt activities to

- Decrease a lot (1), decrease (2), stay the same (3), increase (4), increase a lot (5)

3. In the years to come, I trust the government to do what is right for Tanzania

- Strongly disagree (1), disagree (2), stay the same (3), agree (4), strongly disagree (5)

Question 1 is intended to capture support for the tax system/willingness to pay taxes. Question 2 is intended as a proxy for the respondent's own willingness to engage in corrupt activities. Question 3 measures trust in the government.

In addition to the main outcome variables, we pose questions on other aspects of tax, corruption and trust, as well as on expectations about provision of public services in the future. These questions will aid our understanding of the respondents' answers to the main outcome questions.

Finally, we ask two questions about the degree to which the respondents care about their fellow Tanzanian citizens as well as future generations. The answers to these questions will help us understand how the treatments affected the mindset of respondents.

\section{The sequence of questions}

The mentioning of corruption could affect the answers given to subsequent questions, and we therefore pose the questions related to corruption towards the end of the survey. The questions about the well-being of fellow Tanzanians and future generations are constructed to check whether the treatments affected the respondents in the intended way, i.e. if the per capita treatments puts respondents in an individualistic mindset and the interest rate treatments makes the respondent care more about future generations. Ideally, we should therefore ask these questions directly after the video. However, this could weaken the effects of the treatments on the primary outcomes and we therefore chose to pose them just before the corruption outcomes.

\subsubsection{Behavioural measures}

In the last part of the survey, participants are randomly assigned to play one of the following two games.

\section{Trust game}

This game intends to capture the degree of trust in economic decisions. In the game, the enumerator will give the respondent an amount of money, Tsh 5000. The respondent is then asked to choose how much of this amount he/she wants to send to a Tanzanian citizen. The money sent to the citizen will be tripled in size, to for instance Tsh 15000 if the whole amount is sent. The citizen will then decide how much of the money to send back to the respondent, for instance Tsh 7500. In practise, the amounts sent back will be pre-registered by asking a selection of ten ordinary Tanzanians how much they would send back to the respondent for a given amount. We will ask one respondent how much he/she would return if Tsh 500 was sent (Tsh 1500 received), one respondent how much he or she would return if Tsh 1000 was sent (Tsh 3000 received), one respondent how much he or she 
would return if Tsh 1500 was sent (Tsh 4500 received), etc. Both senders and returners will receive instructions that truthfully state what happens in the game, thus there is no deception involved.

The higher the amount sent to the citizen, the larger is the trust, and we are interested in the difference in trust-levels between treatment and control groups, and between different treatments. Using this method, trust can be measured behaviourally at the individual level. Note that this trust game is slightly complicated to analyse, since sending behaviour may also be driven by risk attitudes and other pro-social elements. The design is not intended to disentangle these issues, but they should be kept in mind and discussed in our paper.

\section{Cheating game}

This game intends to provide a behavioral proxy for people's willingness to get involved in rentseeking/corrupt activities. In the game, the respondent is asked to flip a coin six times without the enumerator observing the results. The respondent will then report how many heads he/she got and is paid an amount of money, for instance Tsh 1000 per heads flipped. The payment scheme is announced before the respondent flips the coin. There is no way for the enumerator to know whether the respondent reports the true result or not.

The idea here is to compare the average number of heads reported between the treatment and control groups, and compare these averages to the expected statistical average for coin flips. Using this method, we can measure average cheating in each group. If we find the average reported number of heads to be higher than three in a group, this is an indication that the respondents in this group are cheating and reporting a higher number of heads than what they are actually tossing. This method thus gives us a behavioural measure of whether expectations about gas revenues increase cheating behaviour in society.

The exact instructions are provided in Appendix B.

\subsection{Power calculations}

To inform the power calculations, we did a web-based experiment in Norway. While the Norwegian context is obviously very different from the Tanzanian, more suitable data do, to our knowledge not exist, and the Norwegian data are the best option we have.

\subsubsection{Calculations for Tanzania}

For the survey experiment, the sample size is powered to detect differences between all four treatment groups seen as a whole and the control group, for all the three main outcomes defined above. We adjust for multiple hypothesis testing using the Benferroni correction. This is the simplest, but most conservative way to control for familywise error rates. With the planned sample of 3000 observations (distributed as 1000 observations in the control group, and 500 observations in each of the four treatment groups) we can detect effect sizes of $0.2 \mathrm{SD}$ between treatment and control outcomes with a power of $99 \%$. The planned sample will also allow us to detect effect sizes of 0.2 SD with a power of $78 \%$.

\section{Empirical strategy}

The analysis will be divided into three parts: main analysis, mechanisms, behaviour and robustness analysis.

\subsection{Main analysis}

The main analysis will address our main question of interest:

How do expectations about resource revenues in a country affect 
- people's willingness to pay taxes?

- people's willingness to engage in corrupt/rent-seeking activities?

- people's trust in the government?

We study this by comparing the control group to all the information groups collapsed together on these three primary outcome variables. In addition, we also shed light on the main research question by conduction two incentivized games that study trust, and willingness to engage in cheating.

We formulate the following hypothesis

Hypothesis 1 Expectations about future gas revenue does not affect willingness to pay taxes, willingness to engage in corrupt activities or trust in the government.

Our main alternative hypotheses are that expectations about gas revenue cause respondents to

- be less willing to pay taxes

- be more willing to engage in corrupt activities

- have less trust in the government

While this is the predicted direction of effects in our alternative hypotheses, we acknowledge that there also exist plausible reasons for why these effects may go in the opposite direction as well. For instance, if people expect the provision of public services to improve in the future, this might lead citizens to be more willing to pay higher taxes in the future.

\subsubsection{Heterogeneity}

We will also study heterogeneity in the treatment effect of reminding respondents about gas revenue by using the background data collected in the survey. We will focus on occupation, education, gender and region.

- Gender: Dummy variable $(1=$ Male, $0=$ Female $)$

- Occupation: Dummies for unemployed, self-employed, public sector and private sector.

- Education: Dummies for no formal education, completed primary school, completed secondary school, higher education

- Region: Dummy variable $(1=$ Dar es Salaam, $0=$ all other regions $)$

\subsection{Mechanisms}

To better understand the findings in the main analysis, we will use the other outcome variables to shed light on potential mechanisms driving the results and the extent to which changes in the primary outcomes also spill over to changes in behavior.

- If a political party advocates an increase in taxes paid by ordinary Tanzanian citizens, like the VAT, my support for that party will

- Can shed light on whether reduced willingness to pay taxes also spills over to voting behavior

- In the years to come, I expect the provision of public services, such as schooling, health services and roads to 
- Can shed light on whether the responses on willingness to pay taxes are partly driven by expectations about public services

- Income inequality in Tanzania should (...), If a political party advocates a reduction in income inequality my support for that party will(...) and In the years to come, I expect income inequality to (...)

- Can shed light on whether the changes in primary outcomes partly are driven by changes in peoples views and expectations about inequality.

- Generally, I trust my fellow citizens

- Can shed light on whether the change in trust in government is a general change in trust.

- People should never engage in corrupt activities and I believe that my fellow citizens would engage in corrupt activities if the could benefit economically from it

- It can shed light on whether changes in peoples expectations about the extent of corrupt activities in the future partly reflects changes in their own normative views on corruption or in belief's about other people's engagement in corruption

We study the impact on these additional outcomes in the same way as in the main analysis. We formulate the following hypotheses:

Hypothesis 2 Willingness to pay taxes does not spill over to support for political parties.

The alternative hypothesis is the respondents who support a higher tax level in the future is also more supportive of political parties that advocate tax increases.

Hypothesis 3 Expectations about future public service provision do not affect willingness to pay taxes.

The alternative hypothesis is that respondents who expect better provision of services in the future are more willing to pay taxes.

Hypothesis 4 People's views of inequalities do not affect willingness to pay taxes, willingness to engage in corrupt activities or trust in the government.

The alternative hypothesis is that people's views of inequalities do affect willingness to pay taxes and that respondents who think income inequalities should be reduced are more willing to pay taxes and support a political party that advocates tax increases.

Hypothesis 5 Trust in fellow citizens is not related to trust in the government.

The alternative hypothesis is that trust in the government also reflects a general environment of trust or mistrust and that trust in fellow citizens is positively related to trust in the government.

Hypothesis 6 Normative views on corruption or belief's about other people's engagement in corruption do not affect willingness to pay taxes, willingness to engage in corruption or trust in the government.

The alternative hypothesis is that normative and positive views on corruption affect willingness to pay tax and trust in the government negatively, and willingness to engage in corruption positively. 


\subsection{Behaviour}

We use the incetivized games to study the effect of expectations about gas revenues on actual behaviour. We define:

- Trust: Count variable $(0,500,1000,1500,2000,2500,3000,3500,4000,4500,5000)$

- Cheating: Average number of LIONS tossed for each group

And hypothesise that

Hypothesis 7 Expectations about gas revenues do not affect trust in other Tanzanians.

Our alternative hypothesis is that expectations about gas revenues cause the respondents to trust other Tanzanians less, i.e. that respondents that receive information about gas revenues send less money to another Tanzanian than respondents that only receive general information about Tanzania. We also hypothesise that

Hypothesis 8 Expectations about gas revenues do not affect willingness to engage in corrupt activites/cheat.

Our alternative hypothesis is that expectations about gas revenues increases the respondents' propensity to engage in corrupt activites/cheat, i.e. that average number of reported LIONS is higher in the treatment than in the control group.

\subsection{Robustness analysis}

To study the robustness of the main results, we run additional treatments where the estimated resources revenues are illustrated in different ways. We here use a $2 \times 2$ design where we study whether the results are sensitive to whether the revenues are illustrated (a) in per capita or population terms and (b) in totals or in terms of the interest that can be generated if the money is saved. We believe that this design captures two important entitlement dimensions that easily become salient when communicating about resource revenues; (1) the extent to which the resources revenues are considered to belong to the individuals or to society and (2) the extent to which future generations are considered to be entitled to the resource revenues.

We also test whether these different ways of communicating affect the perceived size of the resource revenues and the extent to which they consider the information to be news to them.

- The well-being of my fellow citizens is important to me and The well-being of future generations is important to me

- Can shed light on whether information about resource revenues changes the importance we attach to others and to future generations

- How much of this information was new to you? and Did you find the estimated gas revenues larger than expected?

- Can shed light on whether the information provided served as a reminder or an information shock, and whether the different ways of communicating affected perceived size of resource revenues.

Our main test in this part is whether the four information treatments differ in terms of how they affect the three primary outcome variables, and we formulate the following hypothesis.

Hypothesis 9 The way information about gas revenues is formulated does not affect willingness to pay taxes, willingness to engage in corrupt activities or trust in the government. 
Our alternative hypotheses are that communicating in per capita terms makes people more individualistic and that communicating in terms of real returns to savings makes people care more about future generations. In other words, we hypothesise that the information phrased in per capita terms makes people less willing to pay taxes, more willing to engage in corruption, and trust the government less than the information phrased in population terms because the latter emphasises the society and increases the feeling of togetherness. This might induce respondents to care more about their fellow citizens and increase willingness to contribute to a positive development. Similarly, we hypothesise that the information phrased in terms of interest makes people more willing to pay taxes, less willing to engage in corrupt activities and trust the government more than information phrased in total value terms because it emphasises, and induce the respondents to care more for, the future generations of Tanzanians.

\subsection{Specification and analysis}

We here provide the main robust OLS regressions that will be used in the analysis. Because the outcome variables are discrete, we will also estimate ordered and binary logit models as robustness checks. For the binary logit model, we will define the variables to take the value of one if the respondents answer 4 or 5 (increase/agree or increase a lot/strongly agree) and zero otherwise.

\subsubsection{Main hypothesis}

In the main part of the analysis, we focus on differences in outcomes between all the treatment groups seen as a whole and the control group. Hypothesis 1 will be tested by estimating the following OLS regressions for each of the three outcome variables:

$$
y_{i}^{j}=\alpha^{j}+\beta_{T}^{j} T_{i}+\varepsilon_{i}^{j}
$$

Where $y_{i}^{j}$ is the outcome of main variable $j=1,2,3$ for individual $\mathrm{i}$, and $T_{i}$ is an indicator taking the value 1 if individual $\mathrm{i}$ was in one of the four treatment groups. The formal statements of hypothesis 1 is given in appendix A. To control differences in background variables, we also estimate

$$
y_{i}^{j}=\alpha^{j}+\beta_{T}^{j} T_{i}+\beta_{X}^{j} X_{i}+\varepsilon_{i}^{j}
$$

where $X_{i}$ is a vector of the background variables as defined in section 3.1.1 above.

\subsubsection{Heterogeneity analysis}

The heterogeneity analysis for gender will be conducted by estimating the following regression for Hypothesis 1

$$
y_{i}^{j}=\alpha^{j}+\beta_{T}^{j} T_{i}+\beta_{M}^{j} M_{i}+\beta_{T M}^{j} T_{i} M_{i}+\varepsilon_{i}^{j}
$$

where $M_{i}$ is a dummy variable taking the value of 1 for male, and 0 for female, respondents. The heterogeneity analysis for the other background variables will follow the same logic.

\subsubsection{Mechanisms}

The analysis of mechanisms and Hypothesis 2-6 will be conducted using the approach of the main analysis.

\subsubsection{Behaviour}

The analysis of behaviour and Hypothesis 7 and 8 will be conducted using the approach of the main analysis. 


\subsubsection{Robustness analysis}

The robustness analysis will be conducted by estimating the following regression for Hypothesis 9 for each of the three outcome variables.

$$
y_{i}^{j}=\alpha^{j}+\beta_{T 1}^{j} T 1_{i}+\beta_{T 2}^{j} T 2_{i}+\beta_{T 3}^{j} T 3_{i}+\beta_{T 4}^{j} T 4_{i}+\varepsilon_{i}^{j}
$$

Where $T 1_{i}, T 2_{i}, T 3_{i}, T 4_{i}$ are dummy variables taking the value of for respondents in treatment 1 , 2,3 and 4 respectively, and zero otherwise, for individual i.

\section{References}

Andersen, J. J. \& Aslaksen, S. 2013. Oil and political survival. Journal of Development Economics, 100, 89-106.

Aslaksen, S. 2010. Oil and democracy: More than a cross-country correlation? Journal of Peace Research, 47, 421-431.

Brutigam, D., Fjeldstad, O.-H. \& Moore, M. 2008. Taxation and state building in developing countries: Capacity and consent, Cambridge University Press.

Busse, M. \& Gröning, S. 2013. The resource curse revisited: governance and natural resources. Public Choice, 154, 1-20.

Collier, P. \& Hoeffler, A. 2004. Greed and grievance in civil war. Oxford Economic Papers, 56, 563-595.

Leite, C. \& Weidmann, J. 2002. Does Mother Nature Corrupt? Natural Resources, Corruption and Economic Growth. In: Abed, G. \& Gupta, S. (eds.) Governance, corruption and economic performance. Washington: International Monetary Fund.

McGuirk, E. 2013. The illusory leader: natural resources, taxation and accountability. Public Choice, 154, 285-313.

Mehlum, H., Moene, K. \& Torvik, R. 2006. Institutions and the Resource Curse. The Economic Journal, 116, 1-20.

Paler, L. 2013. Keeping the public purse: An experiment in windfalls, taxes and the incentives to restrain. American Political Science Review, 107, 706-725.

Robinson, J. A., Torvik, R. \& Verdier, T. 2006. Political foundations of the resource curse. Journal of Development Economics, 79, 447-468.

Ross, M. L. 2001. Does Oil Hinder Democracy? World Politics, 53, 325-361.

Ross, M. L. 2009. Oil and Democracy Revisited. Working Paper. UCLA Department of Political Science.

Ross, M. L. 2012. The Oil Curse: How Petroleum Wealth Shapes the Development of Nations, Princeton, Princeton University Press. Sachs, J. D. \& Warner, A. M. 1995. Natural resource abundance and economic growth. NBER Working Paper No. 5398.

Sachs, J. D. \& Warner, A. M. 1999. The big push, natural resource booms and growth. Journal of Development Economics, 59, 43-76.

Treismann, D. 2007. What have we learned about the causes of corruption from ten years of crossnational empirical research? Annual Review of Political Science, 10, 211-244.

Tsui, K. K. 2011. More Oil, Less Democracy: Evidence from Worldwide Crude Oil Discoveries. The Economic Journal, 121, 89-115.

Vicente, P. C. 2010. Does oil corrupt? Evidence from a natural experiment in West Africa. Journal of Development Economics, 92, 28-38. 


\section{A Hypothesis testing}

On the basis of 1 , we can test Hypothesis 1-5:

\section{A.1 Hypothesis 1, main analysis}

$H 0: \beta_{T}^{1}=\beta_{T}^{2}=\beta_{T}^{3}=0$

$H A: \beta_{T}^{1} \neq 0, \beta_{T}^{2} \neq 0, \beta_{T}^{3} \neq 0$

We believe the most likely alternative hypothesis to be $\beta_{T}^{1}<0, \beta_{T}^{2}>0$ and $\beta_{T}^{3}<0$.

\section{A.2 Hypothesis 8, robustness analysis}

$H 0: \beta_{T 1}^{j}=\beta_{T 2}^{j}=\beta_{T 3}^{j}=\beta_{T 4}^{j}$

$H 1: \beta_{T 1}^{j} \neq \beta_{T 2}^{j} \neq \beta_{T 3}^{j} \neq \beta_{T 4}^{j}$

We believe that the most likely alternative hypothesis to be $\beta_{T 1}^{j}<\beta_{T 2}^{j}$ and $\beta_{T 3}^{j}<\beta_{T 4}^{j}$ for $j=1,3$ and that the effects goes in the opposite direction for $j=2$. In other words, we hypothesize that the per capita formulations decrease willingness to pay tax and trust in the government, and increases willingness to engage in corruption, compared to the total population formulations. Furthermore, we believe that $\beta_{T 1}^{j}>\beta_{T 3}^{j}$ and $\beta_{T 2}^{j}>\beta_{T 4}^{j}$ for $j=1,2$ and that the effects goes in the opposite direction for $j=2$. In other words, we hypothesize that the interest rate formulations increases peoples willingness to pay tax and trust in government, and increases trust in government, compared to the total value formulations.

\section{B Survey}

\section{B.1 Background information}

\section{PART I: BACKGROUND INFORMATION}

Good day. My name is NN and I am from REPOA, an independent research organisation based in Dar es Salaam. I do not represent the government or any political party. We are studying the views of citizens in Tanzania. We would like to discuss these issues with a member of your household. The information obtained here will be treated strictly confidentially. The answers to these questions will be an important input when it comes to prescribing policies to improve the system.

\section{First, we want to know a little bit about you}

\section{What is your marital status?}

Married - Widow(er)- Unmarried - Divorced

\section{How old are you?}

\section{In which region do you live?}

Dodoma - Arusha - Kilimanjaro - Tanga - Morogoro - Pwani - Dar es Salaam - Lindi - Mtwara Ruvuma - Iringa - Mbeya - Singida - Tabora - Rukwa - Kigoma - Shinyanga - Kagera - Mwanza Mara - Manyara - Unguja Kaskazini - Unfuja Kusini - Mjini Magharibi - Pemba Kaskazini - Pemba 
Kusini - Geita - Katavi - Njombe - Simiyu

4. What is your "home" region? I.e. the region where you go most frequently to visit relatives

Dodoma - Arusha - Kilimanjaro - Tanga - Morogoro - Pwani - Dar es Salaam - Lindi - Mtwara Ruvuma - Iringa - Mbeya - Singida - Tabora - Rukwa - Kigoma - Shinyanga - Kagera - Mwanza Mara - Manyara - Unguja Kaskazini - Unfuja Kusini - Mjini Magharibi - Pemba Kaskazini - Pemba Kusini - Geita - Katavi - Njombe - Simiyu

5. What is the highest level of schooling you have completed?

No formal schooling - Some primary school - Primary school completed - Lower secondary (Form 14) - College (after lower secondary) - Upper secondary (form 5-6) - College (after upper secondary) - Some university/University completed - Vocational/adult education classes - Dont know

\section{What is your main occupation?}

Central government employee - Local government employee - Private company employee, international company - Private company employee, domestic company - Self-employed - Employed in NGO (Non-governmental organization) / CSO (Civil society organization)- Farmer - Unemployed - Other (specify) - Dont know

\section{B.2 Treatments}

\section{PART II: Treatments}

I will now show you a video with some information about Tanzania on my tablet. The video has both pictures and sound. When the video starts playing, please let me know if you have problems seeing the pictures or hear the sound. [Hand tablet and headset to respondent and help with adjustment of headset] Press play when you are ready. Please pay careful attention.

\section{B.2.1 Description of treatments}

\section{Slide 1: General introduction (Video 1-5)}

Sound: This video/slideshow will give you some information about Tanzania.

Picture: Map of Tanzania filled with flag

Sound: Tanzania has a population of 49 million

Picture: Map of Tanzania filled with flag and outline of people

Sound: Tanzania is divided in 30 regions

Picture: Map of Tanzania with regions

Sound: The total income of all Tanzanians was estimated to be 81 Trillion Tanzanian Shillings in 
2013.

Picture: Map of Tanzania, filled with flag and outline of people. A 10000 note appears.

Slide 2 (Video 1-4)

Sound: Since 2010, natural gas has been discovered in the ocean outside the Tanzanian coast.

Picture: Map of Tanzania. Gas canisters indicate gas fields off shore Mtwara and Lindi.

Slide 3 (Video 1-4)

Sound: This gas can be extracted and sold, and give a total revenue of 106 Trillion TSh.

Picture: Gas canister, arrow to Tsh 10000 note and arrow to map of Tanzania filled with outline of people.

\section{Slide 4 (Video 1-3)}

Sound: Let us now look at these revenues in a different way.

Picture: Black background, white text.

\section{Slide 5.1 (Video 1)}

Sound: If we as a nation, save the expected revenues from the sale of natural gas at an interest rate of $4 \%$, the interest realized will amount to 95000 Tanzanian Shillings per Tanzanian, every year, for current and future generations.

Picture: 10000 note, arrow to savings box, arrow to Tanzanian and text year 1, arrow to Tanzanian and text year 2, arrow to Tanzanian and text year 3 and arrow to Tanzanian and text forever.

\section{Slide 5.2 (Video 2)}

Sound: If we as a nation save the expected revenues, the interest earned on these savings will amount to 4.3 trillion Tanzanian shillings every year forever.

Picture: 10000 note, arrow to savings box, arrow to map of Tanzania and text year 1, arrow to map of Tanzania and text year 2, arrow to map of Tanzania and text year 3 and arrow to map of Tanzania and text forever.

\section{Slide 5.3 (Video 3)}

Sound: The expected revenues amounts to 2.4 million Tanzanian Shillings per Tanzanian.

Picture: Black background, white text.

\section{Slide 6.1 (Video 1)}

Sound: Extraction of natural gas can give income equal to $95000 \mathrm{TSh}$, per Tanzanian each year for ever. (Given todays population and $4 \%$ interest)

Picture: 10000 note, arrow to Tanzanian and calendar flipping.

\section{Slide 6.2 (Video 2)}

Sound: Extraction of natural gas can give income equal to 4300000000 Tsh, each year for ever. 
(Given todays $4 \%$ interest)

Picture: 10000 note, arrow to Tanzania and calendar flipping.

Slide 6.3 (Video 3)

Sound: Extraction of natural gas can give income equal to 2400000 Tsh per Tanzania.

Picture: 10000 note and arrow to Tanzanian.

Slide 7 (Video 1-5)

Sound: Thank you for listening carefully. Now we would like to ask you a few questions.

Picture: Black background, white text.

\section{B.3 Control questions}

Control question for treatment groups: Did you find the estimated total gas revenues larger than you had expected?

$\operatorname{Yes}(1) \operatorname{No}(2)$

Control question: How much of this information was new to you?

All of it (1) Most of it (2) Some of it (3) Almost none of it (4) None of it (5)

\section{B.4 Attitudes and beliefs}

PART III: Attitudes and beliefs

7. In order for Tanzania to achieve social and economic development in the years to come, the taxes paid by ordinary Tanzanians, like the VAT, should

Decrease a lot - decrease - stay the same - increase - increase a lot

8. If a political party advocates an increase in taxes paid by ordinary Tanzanians, like the VAT, my support for that party will

Decrease a lot - decrease - stay the same - increase - increase a lot

9. In the years to come, I expect the provision of public services, such as schooling, health services and roads to

Worsen a lot - worsen - stay the same - improve - improve a lot

10. Income inequality in Tanzania should

Decrease a lot - decrease - stay the same - increase - increase a lot

11. If a political party advocates a reduction in income inequality, my support for 
that party will

Decrease a lot - decrease - stay the same - increase - increase a lot

12. In the years to come, I expect income inequality to

Decrease a lot - decrease - stay the same - increase - increase a lot

13. In the years to come, I trust the government to do what is right for Tanzania Strongly disagree disagree - neither disagree nor agree - agree strongly agree

14. Generally, I trust my fellow citizens

Strongly disagree disagree - neither disagree nor agree - agree strongly agree

15. The well-being of my fellow citizens is important to me

Strongly disagree disagree - neither disagree nor agree - agree strongly agree

16. The well-being of future generations is important to me

Strongly disagree disagree - neither disagree nor agree - agree strongly agree

17. People should never engage in corrupt activities

Strongly agree agree - neither agree nor disagree - disagree strongly disagree

18. I believe that my fellow citizens would engage in corrupt activities if they could benefit economically from it

Strongly agree agree - neither agree nor disagree - disagree strongly disagree

19. In the years to come, I expect the extent of corrupt activities to

Decrease a lot - decrease - stay the same - increase - increase a lot

\section{B.5 Behavioural measures}

\section{B.5.1 Trust game}

Instructions for pre-registration of amount sent back from Tanzanian citizen

Good day. My name is Name Name and I am from REPOA, an independent research organisation based in Dar es Salaam. I do not represent the government or any political party. We are doing a study for a survey of Tanzanian citizens, and would like you to participate by making an allocation decision. Your decision will be completely anonymous, but will have real consequences for other Tanzanian citizens that we interview later. We will use your decision to determine payment to a number of the individuals we interview, but below we will only explain how it specifically applies to one of the individuals we interview. You will only be paid for one such situation.

An anonymous Tanzanian citizen we interview will receive Tsh 5000 and can choose between keeping the entire amount, sending the whole amount to you, or spilt the amount between the two of you in any way he or she want (in portions of Tsh 500). The amount of money sent to you is tripled in size, meaning that for every Tsh 1000 sent to you, you will receive Tsh 3000. We want you to decide how much of the money you receive you would like to send back. This amount will actually be paid to the Tanzanian citizen. The rest will be paid to you.

Just to make sure that you have understood the task, I will ask you two questions. 
- If a Tanzanian citizen sends Tsh 2000 to you, how much will you receive?

(If the respondent answers Tsh 6000, proceed to next question)

(If the respondent answers anything else that Tsh 6000, say the following:)

(Your answer it not correct. Let me explain again. The amount of money sent is tripled in size, meaning that for every Tsh 1000 sent to you, you will receive Tsh 3000. Let me ask you the question again. If Tsh 2000 is sent to you, how much will you receive?)

(Repeat until the respondent answers correctly, Tsh 6000. Then proceed to the next question)

- For every Tsh 1000 sent to you, how much will you receive?

(If respondent answers Tsh 3000, proceed to allocation decision)

(If respondent answers anything else than Tsh 3000, say the following:

Your answer is not correct. Let me explain again. The amount sent to you will be tripled in size, meaning that for every Tsh 1000 sent to you, you will receive Tsh 3000. Let me ask the question again. If Tsh 1000 is sent to you, how much will you receive?)

Repeat this until the respondent answer correctly, Tsh 3000. Then proceed to the second question)

You are to decide how much to return if the amount sent to you is

Tsh 500 (1000/1500/2000/2500/3000/3500/4000/4500/5000), meaning that the amount you receive is Tsh $1500(3000 / 4500 / 6000 / 7500 / 9000 / 10500 / 12000 / 13500 / 15000)$.

Note: we will ask 10 respondents to make an allocation decision. Each respondent will receive different amounts.

(Enumerator shows the respondent the amount in 500 notes and hands it over to him or her)

Of these Tsh 1500 you receive, how much, if anything, would you like to send back to the anonymous Tanzanian who sent you money? You can send any amount you want (in portions of Tsh 500). Please tell me how much you would like to give back and hand me that amount.

(Enumerator receives Tsh 500 notes (or not) and notes down amount. The survey is completed by saying:)

Thank you for completing this task for me. Your input is of great value to our research!

\section{Instructions for trust game in the field}

I now invite you to make an allocation decision involving real money. In this part of the study, you will be paired with a randomly selected Tanzanian citizen. We have already asked this Tanzanian citizen what he or she would do in the situation we are now going to present to you and we have preregistered his or her response. As we told this person, we will use his or her response to determine the payment to a number of the people we interview, but in the following instructions we simplify 
the presentation and only describe how this will work for you.

I will now give you Tsh 5000 .

(Enumerator hands the respondent Tsh 5000 in Tsh 500 notes)

You can choose between keeping the entire amount to yourself, sending the whole amount to the random Tanzanian citizen, or split the amount between the two of you in any way that you want (in portions of Tsh 500). If you choose to send any money to the Tanzanian citizen, the amount you send will be tripled in size, meaning that for every Tsh 1000 you send, your Tanzanian citizen will receive Tsh 3000 .

Just to make sure that you have understood the task, I will ask you two questions.

- If you send Tsh 2000 to the randomly selected Tanzanian, how much will he or she receive?

(If respondent answers Tsh 6000, please proceed to the next question)

If respondent answers anything else than Tsh 6000, please say the following:

Your answer is not correct. I will explain one more time. The amount you send will be tripled in size, meaning that for every Tsh 1000 you send, your Tanzanian citizen will receive Tsh 3000. I will ask the question once again. If you send Tsh 2000 to the randomly selected Tanzanian you have been paired with, how much will he or she receive?

Repeat this until the respondent answer correctly, Tsh 6000. Then proceed to the second question)

- For every Tsh 1000 you send to the randomly selected Tanzanian, how much will he or she receive?

(If the respondent answers Tsh 3000, please proceed to the allocation decision]

(If respondent answers anything else than Tsh 3000, say the following:

Your answer is not correct. I will explain one more time. The amount you send will be tripled in size, meaning that for every Tsh 1000 you send, your Tanzanian citizen will receive Tsh 3000. I will ask the question once again. For every Tsh 1000 you send to the randomly selected Tanzanian you have been paired with, how much will he or she receive?

Repeat this until the respondent answer correctly, Tsh 3000. Then proceed to the second question)

I would now like you to tell me how much, if anything, you would like to send to your Tanzanian citizen. Please take this amount from the Tsh 5000 and give it to me.

(Respondent hands money over to enumerator who notes down the amount given and checks the table [to be included] to find the amount to be given back)

Thank you for your decision. The randomly selected Tanzanian citizen has told us that if receiving this amount of money, he or she returns Tsh XXX back to you.

(Enumerator hands Tsh XXX to the respondent)

This was the final part of the survey. Thank you for completing this task for me and for answering my questions. Your input is of great value to our research! 


\section{B.5.2 Cheating game}

Instructions for the field survey

I now invite you to perform a task. First, I will demonstrate what I want you to do.

(Enumerator shows respondent a Tsh coin)

This coin has two sides. One with the picture of $\mathrm{X}$ and one with the picture of $\mathrm{Y}$. I would like you to flip the coin like this

(Enumerator flips the coin, grabs it and puts it on top of his/her wrist, holding the other hand on top of the coin. He/she then lifts her upper hand to look at which side of the coin is up, but makes sure that the coin is only visible to him or her, and not to the respondent)

and to repeat this 6 times. I will ask you to do the flipping of the coin in privacy, and then come back and report the number of times the $\mathrm{X}$ side was up. When you have completed the task, I will pay you Tsh 1000 for each X.

Just to make sure that the task is understood, I will ask you two questions:

- If you get X 5 times, how much will I pay you?

(If respondent answers Tsh 5000, proceed to second question.)

(If respondent answers anything else than Tsh 5000, say the following:

Your answer is not correct. Let me explain again. For every X you get, I will pay you 1000 Tsh. Let me aske the question again. If you get $\mathrm{X} 5$ times, how much will I pay you?

Repeat this until the respondent answer correctly, Tsh 5000. Then proceed to the second question)

That is correct. Let me ask you in a different way.

- How much will I pay you for each X?

(If respondent answers Tsh 1000, proceed to second demonstration.)

(If respondent answers anything else than Tsh 1000, say the following:

Your answer is not correct. Let me explain again. For every X you get, I will pay you 100)

(Proceed to second demonstration)

I will demonstrate once more before you can proceed to flip the coin.

(Enumerator repeats demonstration of coin flipping, and hands the coin over to the respondent)

Please flip the coin 6 times and count how many times the $\mathrm{X}$ side is up. You will do the coin flips 
in privacy. Please step away while you complete the task and return to me when you are done.

(Enumerator waits for the respondent to complete and call him/her back)

Thank you for completing this task for me. How many X did you get?

(Enumerator notes down number of $\mathrm{X}$ and completes the survey by saying:)

This was the final part of the survey. Thank you for your participation. It has been of great value to our research!

That was the final part of the interview. Thank you again for taking the time to answer our questions. Your responses have been very helpful!

\section{B.6 Interview and interviewer details}

\section{PART IV: INTERVIEW and INTERVIEWER DETAILS}

\section{Region}

Dar es Salaam (1) - Mtwara (2) - Lindi (3)

\section{District/municipality}

Ilala (Dar es Salaam) (1) - Temeke (Dar es Salaam) - (2) Kiniondoni (Dar es Salaam) - (3) Masasi District (Mtwara) - (4) Masasi Town (Mtwara) (5) - Mtwara Municipal (Mtwara) (6) - Mtwara Rural (Mtwara) (7) - Nanyumbu (Mtwara) (8) - Newala (Mtwara) (9) - Tandahima (Mtwara) (10) - Kilwa (Lindi) (11) - Lindi District (Lindi) (12) - Lindi Municipal (Lindi) (13) - Liwale (Lindi) (14) - Nachingwea (Lindi) (15) - Ruangwa (Lindi) (16)

22. Ward [Spell name]

23. Area [Spell name]

24. Gender of respondent Male (1) - Female (2)

25. Interviewer's name

26. Interviewer's age

27. Interviewer's gender Male (1) - Female (2) 